\title{
LIBERTAD DE EXPRESIÓN Y DISCURSO DEL ODIO
}

\section{FREEDOM OF EXPRESSION AND HATE SPEECH}

\author{
Juan Manuel López Ulla \\ Universidad de Cádiz, UCA, Cádiz, Espanha
}

\begin{abstract}
Resumen: Este trabajo advierte las dificultades para definir el discurso del odio en la práctica. También demostramos que el Tribunal Europeo de Derechos Humanos no tiene un criterio claro en relación con la utilización de los artículos 17 y 10.2 del Convenio Europeo de Derechos Humanos cuando el demandante invoca la lesión del derecho a la libertad de expresión.
\end{abstract}

Palabras clave: Libertad de expresión; Discurso del odio; Tribunal Europeo de Derechos Humanos.

Summary: This paper warns about the difficulties in defining hate speech in practice. We also show that the European Court of Human Rights does not have a clear criterion regarding the use of articles 17 and 10.2 of the European Convention on Human Rights when the applicant complains under article 10 that his freedom of expression had been violated.

Keywords: Freedom of expression; Hate speech; European Court of Human Rights.

\section{La libertad de expresión como garantía institucional de la Democracia y la dignidad humana como valor fundamental del Estado Constitucional}

La libertad de expresión es un derecho en el que fácilmente apreciamos una doble dimensión. En primer lugar destacamos su naturaleza subjetiva, en cuanto que se trata de un derecho de la persona. A este respecto no es necesario recordar que derechos subjetivos hay muchos en nuestros ordenamientos, y que todos no tienen la misma relevancia. Los reconocidos en las Constituciones o en las Cartas internacionales de derechos suelen tener un carácter principal que normalmente no tienen aquellos que se reconocen en normas de inferior jerarquía; y dentro de los que tienen ese rango constitucional o convencional, tampoco todos tienen el mismo grado de protección, siendo que éste se concede en función de la importancia de aquellos. Pues bien, la libertad de expresión es un derecho consustancial con la naturaleza humana, esto es, imprescindible para el desarrollo de la persona, inextricablemente unido a su dignidad. Se trata, en este sentido, 
de un derecho de máximo nivel, por lo que recibe el mayor grado de protección ${ }^{1}$.

Pero además, la libertad de expresión también tiene una dimensión pública o colectiva que lo vincula de forma inseparable con la democracia, esto es, con el sistema político que se sustenta en el derecho del pueblo soberano a elegir y controlar a sus gobernantes. Efectivamente, sólo cuando la acción de los responsables públicos se somete al escrutinio de los ciudadanos, sólo cuando éstos pueden conocer cómo se toman las decisiones que les afectan, cómo se manejan los fondos públicos o bajo qué criterios actúan las instituciones, el pueblo estará en condiciones de participar efectivamente en el proceso de toma de decisiones. No hay régimen constitucional ni gobierno democrático sin la posibilidad de valorar, criticar o cuestionar el ejercicio del poder político. Esta relación "estrecha", "indisoluble", "esencial", "fundamental" entre la libertad de expresión y la democracia representa el espíritu que inspira la jurisprudencia del Tribunal Europeo de Derechos Humanos (en adelante, TEDH) ${ }^{2}$.

${ }^{1}$ Sobre la doctrina del Tribunal Constitucional español en relación con las libertades de expresión e información, LÓPEZ ULLA, Juan Manuel. Libertad de informar y derecho a expresarse. La jurisprudencia del Tribunal Constitucional: Servicio de Publicaciones de la Universidad de Cádiz, 1994.

${ }^{2}$ El artículo 10.1 del Convenio Europeo de Derechos Humanos, en la parte que ahora nos interesa, dice así: "Toda persona tiene derecho a la libertad de expresión. Este derecho comprende la libertad de opinión y la libertad de recibir o de comunicar informaciones o ideas sin que pueda haber injerencia de autoridades públicas y sin consideración de fronteras [...]”. El TEDH viene recordando esta íntima e inextricable vinculación entre libertad expresión y democracia desde la Sentencia Handyside c. el Reino Unido, n. 5493/72, de 7 de diciembre de 1976 , $\$ 49$. Otra Sentencia señera que subraya la necesidad de tomar en consideración este carácter institucional que la libertad de expresión tiene a la hora de ponderar el ejercicio de los derechos en conflictos es la dictada en el caso Lingens c. Austria, n. 9815/82, de 8 de julio de 1986, $\$ 41$. En el mismo sentido, entre otras, Castells c. Espańa, n. 11798/85, de 23 de abril de 1992; Prager y Oberschlick c. Austria, n. 15974/90, de 26 de abril de 1995; Goodwin c. el Reino Unido, n. 17488/90, de 27 de marzo de 1996 (Gran Sala); Bowman c. el Reino Unido, n. 24839/94, de 19 de febrero de 1998; Soulas y otros y otros c. Francia, n. 15948/03, de 10 de julio de 2008. Sobre la relación entre libertad de expresión y democracia: STUART MILL, John. Sobre la libertad y otros escritos: Ministerio de Trabajo y Seguridad Social, 1991; DE TOCQUEVILLE, Alexis. La democracia en América: Alianza editorial, 1989; BOBILLO, Francisco, J.. La opinión pública. Revista de Estudios Políticos, n. 58, 1987, p. 37 60; DE CARRERAS, Francesc. La libertad de expresión: un derecho constitucional. En: Libertad de expresión, Anuario 1990: PPU, 1991, p- 11-35; FERNÁNDEZ SEGADO, Francisco. La libertad de expresión en la doctrina del Tribunal Europeo de Derechos Humanos. Revista de Estudios Políticos, n. 70, 1990, p. 93-124; PÉREZ LUÑO, Antonio E.. Derechos humanos, Estado de Derecho y Constitución: Tecnos, 1990; SALVADOR CODERCH, Pablo, y otros. El mercado de las ideas: Centro de Estudios Constitucionales, 1990; SÁNCHEZ FERRIZ, Remedio. Estudios sobre las libertades públicas: Tirant lo Blanch, 1989; SÁNCHEZ GONZÁLEZ, Santiago. La libertad de expresión: Marcial Pons, 1992; SANTAOLALLA LÓPEZ, Fernando. La 
El honor, la intimidad y la propia imagen son los derechos que con más frecuencia colisionan con la libertad de expresión ${ }^{3}$. Si ésta es una garantía institucional de la democracia, como acabamos de recordar, aquellos son derechos imprescindibles para salvaguardar la dignidad de la persona, valor fundamental del Estado Constitucional. Es por ello que cuando surge el conflicto, el juez ha de ponderar el ejercicio de uno y otro para resolver el problema. El carácter institucional de la libertad de expresión no lo convierte en un derecho preferente en cualquier caso sino tan sólo cuando cumpla con la función social o colectiva que acabamos de subrayar ${ }^{4}$.

\section{No todo cabe dentro de la libertad de expresión}

Determinar cuándo el ejercicio de la crítica excede de lo permitido no es tarea que pueda resolverse en abstracto. Las opiniones exageradas están protegidas hasta un cierto punto. Ese límite hay que determinarlo atendiendo a las del caso concreto, esto es, al contexto, al medio utilizado

jurisprudencia del Tribunal Constitucional sobre la libertad de expresión: una valoración. Revista de Administración Pública, n. 128, 1992, p. 185-223.

${ }^{3}$ En relación con los derechos al honor, a la intimidad ya la propia imagen como límites a las libertades de expresión e información: SOLOZABAL ECHEVARRÍA, Juan José. Libertad de expresión y derecho a la intimidad de los personajes públicos no políticos. Anuario de Derecho Constitucional y Parlamentario de la Comunidad Autónoma de Murcia, n. 2, 1990, p. 55-89; SEMPERE RODRÍGUEZ, César. Artículo 18. En ALZAGA VILLAAMIL, Óscar. Comentario a las leyes políticas. Constitución española: EDERSA, 1984, p. 426-465; ROMERO COLOMA, Aurelia María. Derecho a la intimidad, a la información y proceso penal: Colex, 1987; RODRÍGUEZ MOURULLO, Gonzalo. Liberta de expresión y derecho al honor: criterios jurisprudenciales para la resolución de los conflictos. En Estudios sobre la Constitución española. Homenaje al prof. Eduardo García de Enterría, Vol. II: Civitas, 1991, p. 893-906; PARDO FALCÓN, Javier. Los derechos del artículo 18 de la Constitución española en la jurisprudencia del Tribunal Constitucional. Revista Española de Derecho Constitucional, n. 32, 1992, p. 141-178; MUÑOZ MACHADO, Santiago. Información y derecho al honor: la ruptura del equilibrio. Revista Española de Derecho Administrativo, n. 74, 1992, p. 165-175; LÓPEZ GUERRA, Luis. La libertad de información y el derecho al honor. Revista del Poder Judicial, n. especial VI, 1989, p. 285-296. GONZÁLEZ PÉREZ, Jesús. La degradación del derecho al honor (honor y libertad de información): Civitas, 1993. PÉREZ DE LOS COBOS, ORIHUEL, Francisco. Sobre el derecho a la propia imagen (a propósito de la STC 170/1987, de 30 de octubre). Revista del Poder Judicial, n. 10, 1988, p. 75-82.

${ }^{4}$ Véase, FERNÁNDEZ MIRIANDA Y CAMPOAMOR, Alfonso. Artículo 20. En ALZAGA VILLAAMIL, Óscar. Comentarios a las leyes políticas. Constitución espańola de 1978: EDERSA, 1984, Vol. II, p. 491-554; GARCÍA HERRERA, Miguel Ángel. Estado democrático y libertad de expresión. Revista de la Facultad de Derecho de la Universidad Complutense, n. 64 y 65, 1981/2, p. 141-174 y 147-201; CHINCHILLA MARÍN, Carmen. Derecho de información y opinión pública libre. Revista del Poder Judicial, n. 3, 1986, p. 61-75.

fragmentum, n. 50, Jul./Dez. 2017. 
para difundirla, a la intención o ánimo del autor y sobre todo al contenido. Con todo, el TEDH ha identificado algunos elementos a tener en cuenta 5 .

En primer lugar, podemos decir que la libertad de expresión estará especialmente protegida cuando la opinión o la información se vierten con ocasión de un debate político o sobre cuestiones de interés general. En este terreno, la crítica tiene un mayor espacio, y cualquier límite o restricción habrá de estar especialmente justificado ${ }^{6}$.

En segundo lugar, el TEDH recuerda que aún en estos ámbitos, no todo cabe bajo el paraguas de la libertad de expresión refiriéndose especialmente al discurso discriminatorio, racista, xenófobo, homófobo, antisemita, aquel que niega el holocausto, que justifica la política nacionalsocialista, que considera que todo musulmán es un terrorista, y cualquier otro que incite, directa o indirectamente a la violencia.

El odio fundamentado en nacionalismos a ultranza, en fundamentalismos religiosos, aquél que justifica la guerra o la exterminación del diferente, no puede pretender la protección del Convenio Europeo de Derechos Humanos (en adelante, $\mathrm{CEDH}$ ). Los derechos y libertades en él reconocidos, los principios en los que se inspira y los valores que lo sustentan han de estar protegidos de quienes lo invocan precisamente para atacarlos. Este tipo de discurso no cabe, por tanto, dentro de la libertad de expresión que garantiza el artículo $10 \mathrm{CEDH}$.

Ahora bien, para que en puridad podamos hablar de "discurso del odio", es necesario, un elemento esencial: que el mensaje incite directa o indirectamente a la violencia, para lo cual habrá que atender al contenido del mensaje, a la intención, al tono, al contexto, o a cualquier otro elemento que nos conduzca a esta conclusión.

Los poderes públicos tienen el deber de hacer frente a esta violencia articulando las garantías que sean necesarias para que los derechos adquieran toda su plenitud, esto es, para que puedan ser ejercidos y disfrutados realmente. En este sentido se ha pronunciado el TEDH: "la tolerancia y el respeto hacia la igual dignidad de todos los seres humanos forma parte de la esencia de una sociedad democrática y pluralista. Por esta razón, es necesario sancionar y prevenir toda manifestación que incite, promueva o justifique

\footnotetext{
${ }^{5} \mathrm{Al}$ respecto, LÓPEZ ULLA, Juan Manuel. El sentido de la ponderación en las libertades de expresión e información", en Estudios de Derecho Público. Homenaje a Juan José Ruiz-Rico, Vol. I: Tecnos, p. 620-642.

${ }^{6} \mathrm{Al}$ respecto, LÓPEZ ULLA, Juan Manuel. El contenido esencial de las libertades de expresión e información según el Tribunal Constitucional español. En SANDLER, Héctor R., El Cuarto Poder. Expresión, Información y Comunicación Social: Ediar, 1999, p. 245-26.
} 
el odio basado en la intolerancia [...], siempre que tales "restricciones" o "sanciones" sean proporcionadas al objetivo legítimo perseguido". Más adelante insistiremos en este último requisito, fundamental a la hora de valorar el alcance de cualquier medida que restrinja el ejercicio de este derecho: toda injerencia habrá de superar un estricto juicio de proporcionalidad, de forma que la limitación no alcancen a discursos legítimos que merezcan protección. Las autoridades judiciales han de tomar medidas razonables respondiendo de manera proporcionada ${ }^{8}$.

\section{La incitación a la violencia como elemento esencial del discurso del odio}

La incitación directa o indirecta a la violencia es un requisito esencial para hablar de discurso del odio 9 . A continuación veremos algunos casos en los que el TEDH estimó que tal elemento no estaba presente. Todas se resolvieron con una Sentencia estimatoria, esto es, el TEDH consideró que a la luz del artículo 10.2 CEDH, la injerencia no estaba justificada.

Gündüzc. Turquía ${ }^{10}$ : El demandante era miembro de una secta islamista. Durante un debate televisado habló muy críticamente de la democracia, describiendo a las instituciones seculares contemporáneas como "impías", cuestionando ferozmente los principios laicos y democráticos y abogando abiertamente por la introducción de la sharia (cuerpo de Derecho islámico). Fue condenado por los tribunales de su país por incitar abiertamente a la población al odio y la hostilidad por razones religiosas, recordando que la tolerancia y la dignidad de todos los seres humanos representan uno de los pilares básicos de una sociedad democrática. El demandante alegó una violación de su derecho a la libertad de expresión, y el TEDH estimó la demanda al tomar en consideración que las opiniones habían sido vertidas en un programa de televisión al que había sido invitado para que pudiera defender su posición sobre la incompatibilidad de los valores democráticos con el islam, postura ciertamente poco ortodoxa y extremista pero que era públicamente conocida y resultaba de interés general. El Tribunal concluyó que más allá de la vehemencia con la que el demandante había defendido su

\footnotetext{
${ }^{7}$ Gündüz c. Turquía, n. 35071/97, de 4 de diciembre de 2003, $\$ \$ 40$ y 41; Erbakan c. Turquía, n. 59405/00, de 6 de julio de 2006, $\$ 56$.

${ }^{8}$ Por todas, Handyside c. el Reino Unido, cit., $\$ 49$.

9 Sobre el discurso del odio, REVENGA SÁNCHEZ, Miguel (dir.). Libertad de expresión y discurso del odio. Cuadernos del Cátedra de Democracia y Derechos Humanos, n. 12, 2015.

${ }^{10}$ Sentencia de 4 de diciembre de 2003, demanda n. 35071/97.
} 
postura, no podía deducirse que hubiese llamado a la violencia. Defender la sharía no podía ser considerado discurso del odio (parágrafos 43, 52 y 53).

Faruk Temel c. Turquia ${ }^{11}$ : El demandante, presidente de una formación política legal, leyó una declaración a la prensa tras un mitin de su partido, criticando la intervención de Estados Unidos en Irak, el aislamiento del líder de una organización terrorista y la desaparición de personas en manos la policía. Tras su discurso, el demandante fue condenado por defender públicamente el uso de la violencia y otros métodos terroristas.

El TEDH estimó la demanda declarando la violación del artículo 10. Al efecto tomó en consideración que el recurrente había defendido la posición de un partido político sobre un tema que era de interés general y que de sus palabras no podía deducirse que hubiese incitado a la violencia, ni a la insurrección o la lucha armada, por lo que no podía hablarse de discurso del odio.

Dink c. Turquía ${ }^{12}$ : Dink fue director y editor jefe de un semanario bilingüe turco-armenio en Estambul. Tras la publicación de ocho artículos en los que expresó su opinión sobre la identidad de los ciudadanos turcos de origen armenio, fue declarado culpable de "denigrar la identidad turca". Tras esta sentencia fue asesinado al salir de las oficinas del periódico. Los demandantes -familiares-, se quejaron en particular del veredicto de culpabilidad en su contra que, según ellos, lo había convertido en blanco de grupos nacionalistas extremos. El TEDH estimó la demanda al entender que no había habido ninguna necesidad social urgente de declarar a Dink culpable de denigrar la identidad turca; que los artículos por los que había sido condenado no habían incitado a otros a la violencia, la resistencia o la rebelión. Simplemente había transmitido sus ideas y opiniones sobre una cuestión de interés público en una sociedad democrática.

Fáberc. Hungría ${ }^{13}$ : El demandante se quejó de que había sido multado por exhibir la bandera de Árpád a rayas a menos de 100 metros de una manifestación contra el racismo y el odio. El Tribunal declaró la violación del artículo $10 \mathrm{CEDH}$ interpretado a la luz del artículo $11 \mathrm{CEDH}$ (libertad de reunión y asociación), aceptando que la exhibición de un símbolo, que era omnipresente durante el reinado de un régimen totalitario en Hungría, podría crear inquietud entre las víctimas del pasado y sus familiares. El

${ }^{11}$ Sentencia de 1 de febrero de 2011, demanda n. 16853/05.

${ }^{12}$ Sentencia de 14 de septiembre 2010, demandas ns. 2668/07, 6102/08, 30079/08, 7072/09 y $7124 / 09$.

13 Sentencia de 24 de julio de 2012. Segunda Sección, demanda n. 40721/08. Véase en particular los $₫ \$ 37$ a 59 . 
TEDH, sin embargo, encontró que tales sentimientos, por comprensibles que fueran, no podían limitar por sí solos la libertad de expresión; que la mera exhibición de esa bandera no alteró el orden público ni obstaculizó el derecho de los manifestantes a reunirse, ya que no había sido ni intimidante ni capaz de incitar a la violencia; y que las autoridades húngaras no habían justificado el procesamiento y la sanción del demandante. El Tribunal, por ello, declaró que la injerencia en la libertad de expresión del demandante no era compatible con el derecho reconocido en el artículo $10 \mathrm{CEDH}$.

Jersild c. Dinamarca ${ }^{14}: \mathrm{El}$ demandante, periodista, fue declarado culpable y sancionado con una multa por un documental donde tres de sus entrevistados, pertenecientes a un grupo que se hacía llamar "Greenjackets", habían realizado comentarios racistas sobre los inmigrantes y personas de diferentes etnias en Dinamarca. El Tribunal reconoció la violación del artículo $10 \mathrm{CEDH}$ porque consideró que el documental en su conjunto no se había propuesto propagar ideas racistas sino informar al público sobre un tema de relevancia social, distinguiendo entre los comentarios efectivamente racistas que los miembros de los Greejackets habían vertido y la intención del demandante, que no había sido otra que la de exponer, analizar y explicar la realidad de este grupo particular de jóvenes.

Perinçek c. Suiza ${ }^{15}$ : El demandante, un político turco, fue condenado penalmente en Suiza por sostener públicamente, en dos conferencias de prensa y en una reunión de un partido político, que las deportaciones y las masacres masivas sufridas por los armenios en el imperio otomano en 1915 y en los años siguientes eran mentira, que no había habido ningún genocidio. Los tribunales suizos consideraron que tales opiniones, que no contribuían en absoluto al debate histórico, eran racistas y nacionalistas. El TEDH, sin embargo, concluyó que no había sido necesario, en una sociedad democrática, someter al demandante a una sanción penal para proteger los derechos de la comunidad armenia. En particular, el Tribunal tuvo en cuenta los siguientes elementos: las declaraciones se vertieron en el marco de un debate histórico y de interés público sobre la cuestión; tales manifestaciones no constituían una llamada al odio o a la intolerancia; en el ámbito en el que se vierten (Suiza), tales declaraciones no habían provocado un aumento de la tensión entre las comunidades concernidas (armenios y turcos); y la dignidad de los miembros de la comunidad armenia no se había visto afectada hasta el punto de necesitar una respuesta penal en Suiza. Por todo ello, el TEDH consideró que la respuesta en forma de condena penal a tales declaraciones fue excesiva.

\footnotetext{
${ }^{14}$ Sentencia de 23 de septiembre de 1994, demanda n. 5890/89, en particular, $\$ \$ 31$ a 37.

${ }^{15}$ Sentencia de 15 de octubre de 2015, demanda n. 27510/08 (Gran Sala).
} 
Otegi Mondragon c. España ${ }^{16}$ : El demandante, portavoz de un grupo parlamentario separatista vasco de izquierda, se refirió en una rueda de prensa al cierre de un periódico vasco por sus presuntos vínculos con ETA, y a los presuntos malos tratos a las personas detenidas por la policía. En su declaración se refirió al Rey de España como "el jefe supremo de las fuerzas armadas españolas, es decir, el comandante de los torturadores, que defiende la tortura e impone su régimen monárquico a nuestro pueblo a través de la tortura y la violencia". Fue condenado a una pena de prisión por el delito de insulto grave contra el Rey. Alegó una violación de su derecho a la libertad de expresión. El TEDH observa en el parágrafo 54 que "si bien era cierto que algunos de los comentarios fueron hostiles con respecto a la institución de la Corona, no había habido incitación a la violencia y no habían llegado al grado de discurso del odio, lo que a los ojos del Tribunal es el elemento esencial que debe tenerse en cuenta (véase, a contrario, Sürek c. Turquía (n. 1) [Gran Sala], núm. 26682/95, \$ 62, de 1999”.

\section{Respuesta del Tribunal Europeo de Derechos Humanos frente al discurso del odio}

Cuando el TEDH llega a la convicción de que no hubo libertad de expresión sino discurso del odio, responde a la demanda de dos maneras diferentes: bien dictando una decisión de inadmisión, invocando el artículo $17 \mathrm{CEDH}$, o bien desestimándola en Sentencia en virtud del artículo 10.2 $\mathrm{CEDH}$. Veamos estos dos enfoques.

\subsection{El enfoque del artículo 17 del Convenio Europeo de Derechos Humanos}

El artículo $17 \mathrm{CEDH}$, que lleva el epígrafe "prohibición del abuso de derecho", dice así: "Ninguna de las disposiciones del presente Convenio podrá ser interpretada en el sentido de implicar para un Estado, grupo o individuo, un derecho cualquiera a dedicarse a una actividad o a realizar un acto tendente a la destrucción de los derechos o libertades reconocidos en el presente Convenio o a limitaciones más amplias de estos derechos o libertades que las previstas en el mismo".

El TEDH ha señalado que el artículo 17 ha de aplicarse en casos excepcionales, exclusivamente cuando resulte evidente que el demandante

${ }^{16}$ Sentencia de 15 de marzo de 2011, demanda n. 2034/07. 
invoca la libertad de expresión (artículo 10) con el propósito de atacar de manera vehemente e indiscriminada los derechos y libertades consagrados en el Convenio o los valores o el espíritu en él subyacentes ${ }^{17}$. Cuando así sucede, el Tribunal dictará una decisión declarándola inadmisible ratione materiae, esto es, incompatible con el Convenio.

Algunos casos resueltos con ese criterio fueron los siguientes:

Belkacem c. Bélgica ${ }^{18}$ : se refiere a la condena de Belkacem, líder y portavoz de la organización "Sharia4Belgium", que fue disuelta en 2012 por incitación a la discriminación, al odio y a la violencia a causa de unos vídeos colgados en YouTube sobre los grupos no musulmanes y la sharia. El Tribunal observó que el demandante animaba en estos vídeos a que los no musulmanes fueran combatidos y sometidos; consideró que estos comentarios incitaban al odio, la discriminación y la violencia, por lo que convino en que un ataque tan general y vehemente era incompatible con la tolerancia, la paz social y la no discriminación, valores en los que se fundamenta el $\mathrm{CEDH}$, recordando que en decisiones anteriores ya había advertido que incitar a la violencia para establecer la sharia era discurso del odio.

M'Bala M'Bala c. Francia ${ }^{19}$ : En este caso, el demandante había ridiculizado a la comunidad judía con ocasión de un espectáculo teatral en teoría cómico. Con la excusa de entregarle un premio, los actores invitaron al escenario a un académico ya condenado en Francia por haber negado las cámaras de gas en los campos de concentración alemanes. El galardón consistía en un candelabro de tres ramificaciones con una manzana en cada una de ellas, que le fue entregado por alguien que vestía un pijama de rayas que llevaba una estrella cosida con la palabra "judío", y que fue descrita en el espectáculo como una "prenda de luz".

El TEDH consideró que la escena descrita no podía considerarse como perteneciente a una obra satírica o provocativa sino que se trataba de un acto político disfrazado de producción artística, que bajo el pretexto de la comedia incitaba al odio contra el pueblo judío negando el holocausto. Para llegar a esta conclusión, el Tribunal valoró especialmente que "el premiado" fuera una persona ya condenada por negar el exterminio del pueblo judío.

\footnotetext{
${ }^{17}$ Belkacem c. Bélgica, decisión de inadmisión de 27 de junio de 2017 (demanda núm. 34367/14). Segunda Sección, \$31.

${ }^{18}$ Decisión de inadmisión de 27 de junio de 2017.

${ }^{19}$ Decisión de inadmisión de 20 de octubre de 2015 (demanda n. 25239/13): negación del holocausto, odio hacia el pueblo judío.
} 
Garaudy c. Francia ${ }^{20}$ : El demandante había sido condenado en su país por incitación al odio racial y por difamar a la comunidad judía por un libro titulado Los mitos fundadores del Israel moderno, en el que dudaba sobre la realidad del holocausto. El TEDH, reconociendo que cuestionar la existencia de eventos históricos claramente demostrados no puede considerarse que sea fruto de una investigación seria, constata que el verdadero propósito del autor era hacer apología del nacionalsocialismo acusando a las propias víctimas de falsificar la historia ${ }^{21}$.

Pavel Ivanov c. Rusia ${ }^{22}$ : El demandante fue declarado por los Tribunales de su país culpable de incitación pública al odio étnico, racial y religioso, por la publicación de una serie de artículos que retrataban a los judíos como el origen del mal en Rusia, acusándoles de conspiradores y calificando a sus líderes de fascistas. Además, les negaba el derecho a ser considerados una nación y pedía para ellos que fueran excluidos de la vida social. El TEDH reconoció el carácter antisemita de las opiniones del demandante, confirmando las consideraciones realizadas por los tribunales nacionales en torno a la incitación al odio hacia el pueblo judío que tales publicaciones habían pretendido.

Norwood c. el Reino Unido ${ }^{23}$ : El demandante fue condenado en su país por exhibir en su ventana un cartel en el que aparecían las Torres Gemelas en llamas con el lema "islam fuera de Gran Bretańa - protejamos al pueblo británico". En este caso se atacaba a todo un grupo religioso, imputando a todos sus miembros un grave acto de terrorismo.

Glimmerveen y Haqenbeek c. Paises Bajos ${ }^{24}$ : Los demandantes habían sido condenados por distribuir unos folletos solicitando que los holandeses de color tuvieran que abandonar el país. La Comisión Europea de Derechos Humanos declara inadmisible con el argumento de que el artículo 10 del Convenio no podía ser invocado para exprimir ideas discriminatorias por razón de la raza.

\footnotetext{
${ }^{20}$ Decisión de inadmisión de 24 de junio 2003, n. 65831/01: odio racional (antisemitismo), revisionismo y negacionismo.

${ }^{21}$ El Tribunal cita al efecto el caso Marais c. Francia, n. 31159/96, decisión de la Comisión de 24 de junio de 1996.

${ }^{22}$ Decisión de inadmisión, de 20 de febrero de 2007 (demanda n. 35222/04). En relación con el mismo motivo, véase la decisión de inadmisión, de 2 de septiembre de 2004, demanda $\mathrm{n}$. $42264 / 98$.

${ }^{23}$ Decisión de inadmisión de 16 de julio de 2003, demanda n. 23131/03.

${ }^{24}$ Decisión de inadmisión de 11 de octubre de 1979, demanda n. 8348/78 y 8406/78.
} 


\subsection{El enfoque del artículo 10.2 del Convenio Europeo de Derechos Humanos}

No es discurso del odio todo aquello que supere los límites establecidos en el artículo 10.2 del Convenio. Como ya hemos adelantado, este concepto exige, como uno de sus elementos esenciales, que de forma explícita o implícita haya una incitación a la violencia. Así ha sucedido en discursos, textos, manifestaciones, o representaciones que hicieron apología de la guerra, que negaron el holocausto, que propugnaron la restauración de un régimen totalitario, o cualquier otra manifestación que sea considerada una amenaza grave contra la paz social y que fomente la intolerancia. Cuando es este el caso, el TEDH hace uso del artículo 17 para inadmitir la demanda ratione materiae, como antes hemos visto. De lo contario, el TEDH entra a conocer del fondo del asunto y dicta una Sentencia desestimatoria si considera que el artículo $10 \mathrm{CEDH}$ no ampara al demandante.

Las Sentencias en las que el TEDH examina si hubo o no violación de la libertad de expresión examinan si la injerencia observó los requisitos del artículo 102. Estos son los siguientes:

1.- Que la injerencia esté prevista en la ley (prévue par la loi), lo que exige que la medida adoptada tenga una base legal en Derecho interno, pero también que la norma en cuestión sea accesible a la persona concernida para que tenga la posibilidad de prever las consecuencias de sus actos.

2.- Que la injerencia tenga como objetivo alguno de los señalados en el artículo 10.2 $\mathrm{CEDH}$, a saber: la seguridad nacional, la integridad territorial o la seguridad pública, la defensa del orden y la prevención del delito, la protección de la salud o de la moral, la protección de la reputación o los derechos ajenos, para impedir la divulgación de informaciones confidenciales o para garantizar la autoridad y la imparcialidad del poder judicial.

3.- Que la injerencia sea una medida necesaria en una sociedad democrática. Al efecto, el TEDH comienza siempre recordando que la libertad de expresión representa uno de los pilares esenciales de una sociedad democrática, y que esta se caracteriza por el pluralismo, la tolerancia y un espíritu de apertura; que la libertad de expresión protege no solo las ideas y las informaciones amables o inofensivas sino también aquellas que molestan, inquietan u ofenden; que el paraguas de la libertad de expresión ampara un cierto grado de exageración y de provocación; que el artículo 10.2 CEDH no deja apenas margen para restringir la libertad de expresión en el ámbito del discurso y el debate político, ámbito en el que este derecho 
adquiere la mayor importancia; más aún cuando es un representante del pueblo, especialmente cuando se trata de un parlamentario de la oposición. Dicho ésto, el TEDH recuerda que la libertad de expresión no es un derecho absoluto, que el legislador puede restringir su ejercicio en casos debidamente justificados, pero que los límites han de ser interpretados restrictivamente.

A continuación, el TEDH suele advertir que si bien la libertad de expresión tiene la importancia que acabamos de subrayar, la tolerancia y el respeto a la igual dignidad de las personas constituyen uno de los fundamentos de una sociedad democrática y pluralista, y que por ello resulta legítimo sancionar y prevenir cualquier manifestación que propague, anime, promueva o justifique el odio fundado en la intolerancia, siempre que tales medidas sean proporcionadas al objetivo legítimo perseguido ${ }^{25}$.

Para advertir si la injerencia ha sido necesaria en una sociedad democrática, el Tribunal, a la luz de las circunstancias del caso concreto (esto es, teniendo presente el momento y el lugar donde se realizan las manifestaciones, el tono y la intención del conjunto de la obra, del discurso, o de la manifestación, y valorando el impacto que provoque las acciones sancionadas por las autoridades nacionales), debe comprobar si la medida adoptada por las autoridades nacionales obedecía a una necesidad social imperiosa (besoin social impérieux). Al efecto, si bien los Estados parte tienen un cierto margen de apreciación, el TEDH puede supervisar si el límite fue compatible con el Convenio, si los motivos invocados por las autoridades nacionales para justificar la injerencia fueron "pertinentes y suficientes", y por último si la medida adoptada fue proporcional al objetivo legítimo perseguido. Veamos algunas Sentencias desestimatorias que siguieron este esquema:

Balsyté-Lideikiene c. Lituania ${ }^{26}$ : La demandante, lituana propietaria de una editorial, es condenada en marzo de 2001 por los tribunales de su país por publicar y distribuir el Calendario lituano 2000, argumentando que promovía el odio étnico contra la población polaca, rusa y judía que vivía en Lituania, debido a las referencias históricas que lo acompañaban. Se le entregó una advertencia administrativa y se confiscaron las copias del calendario no vendidas. El TEDH llega a la conclusión de que la injerencia quiso proteger la reputación y los derechos de los grupos étnicos referidos en ese calendario (parágrafo 73), declarando que la medida había sido necesaria en una sociedad democrática. Para tomar esta decisión valoró el efecto que esta publicación había tenido en el contexto, advirtiendo que

${ }^{25}$ Féret c. Bélgica, cit., $\$ 64$. En relación con el discurso del odio y la apología de la violencia, el TEDH cita, entre otros, Sürek c. Turquía (no 1), cit., $\$ 62$, y Gündüz c. Turquía, cit., $\$ 40$.

${ }^{26}$ Sentencia de 4 de noviembre de 2008 (demanda núm. 72596/01). 
tras la independencia de Lituania, la cuestión territorial y de las minorías étnicas eran temas muy sensibles (parágrafo 78); tuvo en consideración el lenguaje nacionalista y etnocentrista utilizado, que califica de agresivo, concluyendo que estos pasajes contenían declaraciones que incitaban al odio contra los polacos y los judíos, reconociendo que la gravedad de los comentarios justificaba la preocupación de las autoridades lituanas. Por ello, el Tribunal entiende que las autoridades nacionales no habían sobrepasado su margen de apreciación, reconociendo que efectivamente existía una necesidad social imperiosa de adoptar medidas contra la parte demandante (parágrafos 78 a 80), y que la medida ordenada había guardado una relación de proporcionalidad con el objetivo pretendido: proteger la reputación y los derechos de los grupos étnicos que viven en Lituania (parágrafos 81 a 86).

Hemos de señalar que el texto de la Sentencia en ningún momento se refiere a la posibilidad de aplicar el artículo 17. En nuestra opinión, vistos los ejemplos que anteriormente hemos estudiado, hubiera estado justificado, pues consideramos que los comentarios vertidos en este calendario no eran menos graves que aquellos que hemos visto en el epígrafe anterior y que sí justificaron su aplicación.

Féret c. Bélgica ${ }^{27}$ : El demandante era diputado y presidente del partido político Frente Nacional en Bélgica. Durante la campaña electoral distribuyeron varios folletos con las siguientes consignas "contra la islamización de Bélgica", "detengamos la farsa política de integración”, y "envíen a los inmigrantes no europeos a casa". Los órganos jurisdiccionales internos consideraron que tales mensajes contenían elementos que "claramente (...) incitaban si no a la violencia, a la discriminación, a la segregación o al odio en contra de un grupo, de una comunidad o de sus miembros, en razón de la raza, el color, la ascendencia o el origen nacional o étnico" (parágrafo 70) y que encajan en lo que se conoce como "discurso del odio" según el Anexo a la Recomendación n. R(97)20 del Comité de Ministros del Consejo de Europa, de 30 de octubre de 1997. Al respecto, el TEDH advierte que "la incitación al odio no requiere necesariamente un acto de violencia o cualquier otro acto delictivo. Las violaciones de las personas por insultar, ridiculizar o difamar a determinadas partes de la población y grupos específicos de la población o la incitación a la discriminación, como sucede en este caso, son suficientes para que las autoridades prioricen la lucha contra el discurso racista, haciendo frente a un ejercicio de la libertad de expresión irresponsable que socava la dignidad e incluso la seguridad de estos colectivos o grupos de la población. El discurso político que incita al odio basado en prejuicios religiosos, étnicos o culturales representa un

${ }^{27}$ Sentencia de 16 de julio de 2009, demanda n. 15615/07. 
peligro para la paz social y la estabilidad política en los estados democráticos" (parágrafo 73).

Pues bien, a pesar de la gravedad de los mensajes, en este caso el TEDH no aplica el artículo 17. Tampoco el TEDH afirma explícitamente que se trate de un caso de discurso del odio, aunque al aceptar los argumentos de los órganos jurisdiccionales internos (parágrafo 78), implícitamente sí lo hace. Véase en este sentido también, el parágrafo 76 , donde se afirma que el contexto electoral en el que se difundió el mensaje había aumentado su resonancia, incitando claramente al odio racial; y el parágrafo 78, donde reconoce que el lenguaje empleado había "incitado claramente a la discriminación y al odio racial”.

El TEDH no explicó por qué en este caso el artículo 17 no debía aplicarse. El Gobierno así lo había solicitado, alegando que el contenido de los folletos denunciados era totalmente incompatible con la democracia y los derechos humanos, pues alentaban a la discriminación racial y eran absolutamente contrarios a los derechos y valores del Convenio. El Tribunal así lo entendió también, pues de manera un tanto ambigua reconoció que si no a la violencia, el discurso incitaba al odio, pero en este caso decidió admitir la demanda para luego desestimarla ${ }^{28}$. Se trata de otro caso que demuestra que al día de la fecha el criterio para inadmitir (artículo 17) o desestimar (artículo 10.2) una demanda de estas características no está claro.

Vejdeland y otros c. Suecia ${ }^{29}$ : Tampoco en este caso el Tribunal califica los mensajes sancionados por los órganos de la jurisdicción interna como "discurso del odio", lo que motivó que la Sentencia fuera acompañada por tres votos concurrentes, que firmaron cinco de los siete jueces que componían la Sala:

Los demandantes, miembros de una organización llamada National Youth fueron condenados por los tribunales de su país por distribuir en una escuela secundaria superior, concretamente en los armarios de los alumnos, unos 100 folletos que decían que la homosexualidad era una "desviación sexual", que tenía "un efecto moralmente destructivo para la sociedad" y que era responsable del desarrollo del VIH. Los demandantes, invocando la lesión del artículo 10, sostienen que con esos folletos no habían querido expresar desprecio hacia los homosexuales sino abrir un debate sobre la falta de objetividad en la educación en las escuelas de Suecia (parágrafo 54).

\footnotetext{
${ }^{28}$ La Sentencia Féret c. Bélgica se aprobó por cuatro votos contra tres. Fue acompañada de un voto disidente del juez Andràs Sajó, al que se unen los jueces Vladimiro Zagrebelsky y Nona Tsotsoria. Este voto rechaza la ausencia de violación del artículo 10 aduciendo que confirmar la represión penal de un discurso político lesiona la libertad de expresión.

${ }^{29}$ Sentencia de 9 de febrero de 2012, demanda n. 1813/07.
} 
El TEDH, reconociendo que no había existido una incitación directa a la violencia, calificó de graves y perjudiciales el contenido de tales folletos; advirtió que la discriminación por razón de la orientación sexual es tan grave como la que está basada en la raza, el origen o el color; y por ello desestimó por unanimidad la demanda, considerando que la injerencia de las autoridades en el ejercicio de la libertad de expresión había sido necesaria en una sociedad democrática para la protección de la reputación y los derechos de los demás (parágrafo 60).

Los parágrafos clave en esta Sentencia son el 54 y el 55. En el primero, el TEDH reconoce que "si bien estas declaraciones no incitaban directamente a cometer actos de odio, son acusaciones muy graves" ${ }^{30}$. En el segundo recuerda que la incitación al odio no exige necesariamente un llamamiento a un acto de violencia u otros actos delictivos; y que el insulto o la ridiculización o difamación de grupos específicos de la población es una manera irresponsable de ejercer la libertad de expresión que debe ser combatida por las autoridades públicas ${ }^{31}$.

Pues bien, estos comentarios provocaron la redacción de tres votos concurrentes. En dos de ellos se criticó que los comentarios se equipararan al discurso del odio, pues, reconociendo la gravedad de los mismos, y ubicándolos fuera del amparo de artículo 10, no habían incitado a la violencia ${ }^{32}$; y en el tercero se criticó justo lo contrario, esto es, que la Sentencia no hubiera afirmado con claridad que estos mensajes también son discurso del odio ${ }^{33}$. La ambigüedad de la Sentencia y las opiniones que la acompañan demuestran que en la práctica lo que sea discurso del odio no está del todo claro.

Leroy c. Francia ${ }^{34}$ : En "Ekaitza", un semanario vasco-francés, el demandante publica un dibujo que representa el ataque a las torres gemelas del World Trade Center, acompañado de una leyenda que imitaba el lema publicitario de una famosa marca: "Todos lo sońábamos... Hamas lo hizo". Las autoridades jurisdiccionales le condenan y él invoca ante el TEDH la violación de su libertad de expresión.

\footnotetext{
30 "In the Court's opinion, although these statements did not directly recommend individuals to commit hateful acts, they are serious and prejudicial allegations".

${ }^{31} \mathrm{Al}$ respecto cita, entre otros, Smith y Grady c. el Reino Unido, números 33985/96 y 33986 / 96, \$97, de 1999).

${ }^{32} \mathrm{El}$ primer voto concurrente es del Spielmann al que se u ne el juez Nußberger; y el segundo es del juez Zupančič.

${ }^{33} \mathrm{El}$ tercer voto concurrente es del juez Yudkivska, al que se une el juez Villige.

${ }^{34}$ Sentencia de 2 de octubre de 2008, demanda n. 36109/03.
} 
A pesar de la gravedad del dibujo, que en ningún momento se cuestiona, el TEDH decide admitir a trámite la demanda y no aplicar el artículo 17. Lo hace, entre otras consideraciones, señalando que si bien la viñeta hacía referencia a la destrucción del imperialismo norteamericano, ello no significaba que el autor con ello hubiera querido atacar los derechos y las libertades que el Convenio consagra o los valores que lo fundamentan; y reconociendo que no era tan evidente que el dibujo y la leyenda que lo acompańaba hicieran apología del terrorismo, considera que la queja no es incompatible ratione materiae y que debe ser admitida a trámite ${ }^{35}$.

Sin embargo, al analizar el fondo, el TEDH hace algunas consideraciones que parecen no casar bien con el razonamiento que le llevó a no aplicar el artículo $17 \mathrm{CEDH}$. Así, el parágrafo 41 señala que el dibujo denunciado no se limitaba a la crítica del imperialismo norteamericano, sino que postulaba y glorificaba su destrucción violenta; que la leyenda que acompañaba al dibujo expresaba el apoyo moral del caricaturista a los presuntos autores de los atentados del 11 de septiembre de 2001, justificando la violencia perpetrada contra miles de civiles.

Además, en su resolución desestimatoria, el TEDH valora las consecuencias que la publicación tuvo en el momento y en el entorno concreto en el que se difunde: advierte que el dibujo se publica el 13 de septiembre de 2001, esto es, dos días después de los atentados, y reconoce que a pesar de la limitada circulación del semanario, había provocado una reacción pública capaz de generar violencia, con un impacto considerable en el orden público (parágrafo 45).

\footnotetext{
${ }^{35}$ Dice así el $\$ 27$ : “La Cour est d'avis que l’expression litigieuse ne rentre pas dans le champ d'application des publications qui se verraient soustraites par l'article 17 de la Convention à la protection de l'article 10. D'une part, publiée sous la forme humoristique certes controversée d'une caricature, le message de fond visé par le requérant - la destruction de l'impérialisme américain - ne vise pas la négation de droits fondamentaux et n'a pas d'égal avec des propos dirigés contre les valeurs qui sous-tendent la Convention tels que le racisme, l'antisémitisme (Garaudy, précité, Ivanov c. Russie (déc.), no 35222/04, 20 février 2007) ou l'islamophobie (Norwood, précité). D'autre part, nonobstant la qualification d'apologie de terrorisme retenue par les juridictions nationales, la Cour est d'avis que le dessin litigieux et le commentaire qui l'accompagne ne constituent pas une justification à ce point non équivoque de l'acte terroriste qui les feraient échapper à la protection garantie par l'article 10 de la liberté de la presse. Enfin, l'offense faite à la mémoire des victimes des attentats du 11 septembre 2001 à travers la publication litigieuse doit être examinée à la lumière du droit, non absolu, protégé par l'article 10 de la Convention; la Cour a déjà examiné la teneur de propos similaires sous l'angle de cette disposition (Kern c. Allemagne (déc.), no 26870/04, 29 mai 2007). Partant, la liberté d'expression revendiquée par le requérant doit être couverte par cette disposition et son grief n'est pas incompatible ratione materiae avec les dispositions de la Convention au sens de l'article $35 \$ 3$ de la Convention”. Por ello, el TEDH considera que la demanda no puede ser considerada como manifiestamente infundada (\$28).
} 
Por las razones señaladas, el TEDH declara que la medida impuesta a la parte demandante no había sido desproporcionada con respecto al objetivo legítimo perseguido, reconociendo que los motivos invocados por los órganos jurisdiccionales nacionales para condenarla habían sido pertinentes y suficientes (parágrafos 46 y 47). Por todo ello, finalmente, el Tribunal conviene en que la injerencia había sido necesaria en una sociedad democrática, y que por tanto el artículo 10 no había resultado lesionado.

En nuestra opinión, las razones que el Tribunal aporta para no aplicar el artículo $17 \mathrm{CEDH}$ no encajan luego con las consideraciones sobre la incitación a la violencia que el dibujo podría haber provocado. Entendemos que para no aplicar el artículo 17, el Tribunal consideró que la vińeta no amenazaba los derechos y libertades del Convenio, ni los valores en los que éste se fundamenta, y que tampoco representaba una incitación directa o indirecta a la violencia. Sin embargo, las razones que utiliza para justificar que ese dibujo no podía ser considerado una manifestación de la libertad de expresión que el artículo $10 \mathrm{CEDH}$ protege, no creemos que sean menos inquietantes que las que se emplearon en otros casos para inadmitir a trámite la demanda. A nuestro modo de ver, la balanza se inclina de un lado o del otro en función de la sensación de peligro que el Tribunal advierta.

Soulas y otros c. Francia $a^{36}$ : Los demandantes habían sido condenado penalmente por incitar al odio y a la violencia contra las comunidades musulmanas procedentes del norte y centro de África por la publicación de un libro titulado La colonización de Europa: Observaciones verídicas sobre la inmigración y el islam. El TEDH señala que la cuestión de la integración de los inmigrantes en los países de acogida es un debate particularmente intenso en Francia (parágrafo 36 a 39). El parágrafo 40 advierte que el autor trata de demostrar que el islam pretende una conquista hostil de Francia y de Europa, y que la delincuencia juvenil no es más que la expresión del comienzo de una guerra civil étnica por el territorio; que el continente se enfrenta a un caos que pone en riesgo su civilización, señalando que se trata de la amenaza más seria a la que se ha enfrentado Europa, y denunciando la inconsciencia del sueño de una sociedad comunitarista y multiétnica.

En este caso, el TEDH reconoció que varios pasajes del libro ofrecían una imagen negativa de la comunidad inmigrante; que el estilo era polémico y que presentaba los efectos de la inmigración como catastróficos (parágrafo 41); coincidió con los órganos jurisdiccionales nacionales en que las expresiones utilizadas en el libro tenían por objeto suscitar en los lectores un sentimiento de rechazo y antagonismo, exacerbado por el uso del lenguaje militar; que los musulmanes eran identificados como el principal enemigo

\footnotetext{
${ }^{36}$ Demanda núm. 15948/03, de 10 Julio de 2008.
} 
de la patria, transmitiendo la idea de que la solución era emprender una guerra de reconquista étnica; que el libro alertaba incluso sobre el peligro que tenían las jóvenes blancas de ser violadas por los magrebíes (parágrafo 43). Al efecto, el TEDH señaló que los argumentos del Gobierno, que había solicitado la inadmisión de la demanda invocando el artículo $17 \mathrm{CEDH}$, estaban "estrechamente relacionadas con la necesidad de la sanción impuesta en una sociedad democrática", vinculando este aspecto al tema de fondo (parágrafo 23) ${ }^{37}$, razonamiento que a nuestro juicio es tan insuficiente que en realidad deja la solicitud del Gobierno sin responder.

Finalmente, el Tribunal, valorando que la multa no había sido excesiva (parágrafo 46), declara que la injerencia en la libertad de expresión había resultado necesaria en una sociedad democrática. $Y$ en cuanto a la cuestión pendiente sobre la posible aplicación del artículo 17, que el Tribunal vinculó al fondo del asunto, se solventó de forma lapidaria señalando que los comentarios del libro no habían sido lo suficientemente graves como para justificar su aplicación (parágrafo 48) ${ }^{38}$.

İ.A. c. Turquía ${ }^{39}$ : El demandante, propietario y director de una editorial, publicó 2.000 ejemplares de un libro que abordaba cuestiones teológicas y filosóficas en un estilo novelesco. El fiscal de Estambul acusó al demandante de insultar a Dios, a la religión, al profeta y al libro sagrado a través de tal publicación. Los órganos jurisdiccionales nacionales condenaron al demandante a dos años de prisión y al pago de una multa, conmutando inmediatamente la pena de prisión por una pequeña multa. Ante el TEDH, el demandante denuncia que tal sanción había violado su derecho a la libertad de expresión.

El TEDH desestimó la demanda considerando que la medida había resultado necesaria en una sociedad democrática (parágrafo 30). Al efecto, el Tribunal valoró que en el libro no sólo había comentarios inquietantes, molestos o provocativos, sino también un ataque abusivo contra el profeta del islam (parágrafo 29); que a pesar de que en la sociedad turca existía

${ }^{37}$ Parágrafo $\$ 23$ : "La Cour considère que les arguments avancés par le Gouvernement sur le terrain de l'article 17 de la Convention, et donc, de l'applicabilité de l'article 10, sont étroitement liés à la substance des griefs tirés par les requérants dudit article 10, et notamment à la question de la nécessité dans une société démocratique. Elle joint donc l'exception au fond".

$38 \$ 48$ : "Enfin, la Cour considère que les passages incriminés du livre en cause ne sont pas suffisamment graves pour justifier l'application de l'article 17 de la Convention en l'espèce. Partant, elle rejette l'exception du Gouvernement tirée de cet article, et conclut qu'il n'y a pas eu violation de l'article 10 ".

${ }^{39}$ Sentencia de 13 de septiembre de 2005. Demanda núm. 42571/98, Segunda Sección: ataque por motivo religioso. La Sentencia no contiene ninguna referencia sobre el artículo 17 del Convenio. 
una cierta tolerancia a la crítica religiosa, profundamente vinculada al principio de la laicidad, los creyentes podían legítimamente sentir que ciertos pasajes del libro constituían un ataque injustificado y ofensivo sobre cuestiones sagradas para los musulmanes; y que la sanción impuesta no era desproporcionada (parágrafo 32).

\section{Conclusión}

Al final de este trabajo hemos llegado a la conclusión de que si bien en teoría el "discurso del odio" está bien definido, la práctica no siempre resulta tan clarificadora. De ahí la dificultad de encontrar un criterio sobre las circunstancias que pueden justificar la resolución de estos casos mediante la aplicación del artículo $17 \mathrm{CEDH}$.

Efectivamente, cuando el Estado demandado solicita la inadmisión de la demanda invocando el artículo 17, el TEDH nunca ha dado una respuesta clara. A veces contesta señalando que tal motivo está estrechamente ligado a la cuestión de fondo, admitiendo en consecuencia el asunto a trámite y resolviendo el caso en una Sentencia. Y en otras ocasiones se limita a señalar que la inadmisión sólo es posible cuando circunstancias excepcionales lo justifican, pero sin aclarar por qué en asuntos de aparente similitud en la gravedad de las afirmaciones, unas veces se utiliza este enfoque y otras veces no.

En relación con esa falta de claridad que estamos advirtiendo, es paradigmática, entre todas, la Sentencia Vejdeland y otros c. Suecia, que desestima la demanda que había denunciado la violación del artículo 10 $\mathrm{CEDH}$ a raíz de una sanción impuesta por las autoridades suecas contra una organización que había repartido en un colegio folletos criticando la homosexualidad. El Tribunal declaró que aquella información no estaba protegida por la libertad de expresión, pero no la consideró lo suficientemente grave como para justificar la aplicación del artículo 17 CEDH. De tal resolución podríamos deducir que para el TEDH aquellas manifestaciones no fueron discurso del odio, puesto que no incitaban a la violencia, pero la realidad es que de la lectura de los fundamentos jurídicos tal conclusión no se alcanza con claridad, hasta el punto de que por ello, el fallo fue acompańado de tres votos concurrentes.

Las observaciones que hemos realizado en este trabajo no deben entenderse como una denuncia de mala praxis. Determinar qué es un ataque verdaderamente grave contra el Convenio o qué manifestación 
incita directa o indirectamente a la violencia, no se puede evaluar sino a partir de las circunstancias de cada caso concreto, estando tal valoración condicionada, además, por una carga subjetiva imposible de evitar. Como decíamos, el discurso del odio es un concepto fácil de definir en abstracto pero no tanto en la práctica. En nuestra opinión, ésta es la razón por la que en ocasiones el TEDH inadmite la demanda aplicando el artículo 17 del Convenio, mientras que en otras resuelve en Sentencia utilizando el enfoque del artículo 10.2 CEDH.

\section{Casos estudiados del Tribunal Europeo de Derechos Humanos}

Handyside c. el Reino Unido, n. 5493/72, de 7 de diciembre de 1976.

Glimmerveen y Haqenbeek c. Paises Bajos ns. 8348/78 y 8406/78, de 11 de octubre de 1979.

Lingens c. Austria, n. 9815/82, de 8 de julio de 1986.

Castells c. España, n. 11798/85, de 23 de abril de 1992.

Jersild c. Dinamarca, n. 5890/89, de 23 de septiembre de 1994.

Prager y Oberschlick c. Austria, n. 15974/90, de 26 de abril de 1995.

Goodwin c. el Reino Unido, n. 17488/90, de 27 de marzo de 1996.

Marais c. Francia, n. 31159/96, de 24 de junio de 1996.

Bowman c. el Reino Unido, n. 24839/94, de 19 de febrero de 1998.

Smith y Grady c. el Reino Unido, ns. 33985/96 y 33986 / 96, , de 27 de septiembre de 1999.

Garaudy c. Francia, n. 65831/01, de 24 de junio 2003.

Norwood c. el Reino Unido n. 23131/03 de 16 de julio de 2003

Gündüz c. Turquía, n. 35071/97,_de 4 de diciembre de 2003.

İ.A. c. Turquía, n. 42571/98, de 13 de septiembre de 2005.

Erbakan c. Turquía, n. 59405/00, de 6 de julio de 2006.

Pavel Ivanov c. Rusia n. 35222/04 de 20 de febrero de 2007

Soulas y otros y otros c. Francia, n. 15948/03, de 10 de julio de 2008.

Leroy c. Francia, n. 36109/03, de 2 de octubre de 2008.

Balsyté-Lideikiené c. Lituania, n. 72596/01, de 4 de noviembre de 2008.

Féret c. Bélgica, n. 15615/07, de 16 de julio de 2009.

Dink c. Turquía, ns. 2668/07, 6102/08, 30079/08, 7072/09 y 7124/09, de 14 de septiembre 2010 . 
Faruk Temel c. Turquía, n. 16853/05, de 1 de febrero de 2011.

Otegi Mondragon c. España, n. 2034/07, de 15 de marzo de 2011.

Vejdeland y otros c. Suecia, n. 1813/07, de 9 de febrero de 2012.

Fáber c. Hungría, n. 40721/08, de 24 de julio de 2012.

Perinçek c. Suiza, n. 27510/08, de 15 de octubre de 2015.

M'Bala M'Bala c. Francia, n. 25239/13, de 20 de octubre de 2015.

Belkacem c. Bélgica, n. 34367/14, de 27, de junio de 2017.

\section{Referências}

BOBILLO, Francisco, J.. La opinión pública. Revista de Estudios Políticos, n. 58, p. 37-60, 1987.

CHINCHILLA MARÍN, Carmen. Derecho de información y opinión pública libre. Revista del Poder Judicial, n. 3, p. 61-75, 1986.

DE CARRERAS, Francesc. La libertad de expresión: un derecho constitucional. Libertad de expresión, Anuario 1990: PPU, p. 11-35, 1991.

DE TOCQUEVILLE, Alexis. La democracia en América: Alianza editorial, 1989.

FERNÁNDEZ MIRIANDA; CAMPOAMOR, Alfonso. Artículo 20. En: ALZAGA VILLAAMIL, Óscar. Comentarios a las leyes políticas. Constitución española de 1978: EDERSA, Vol. II, 1984, p. 491-554.

FERNÁNDEZ SEGADO, Francisco. La libertad de expresión en la doctrina del Tribunal Europeo de Derechos Humanos. Revista de Estudios Políticos, n. 70, p. 93-124, 1990.

GARCÍA HERRERA, Miguel Ángel. Estado democrático y libertad de expresión. Revista de la Facultad de Derecho de la Universidad Complutense, n. 64, p. 141-174, 1981.

Estado democrático y libertad de expresión. Revista de la Facultad de Derecho de la Universidad Complutense, n. 65, p. 147-201, 1982.

GONZÁLEZ PÉREZ, Jesús. La degradación del derecho al honor (honor y libertad de información): Civitas, 1993.

LÓPEZ GUERRA, Luis. La libertad de información y el derecho al honor. Revista del Poder Judicial, n. especial VI, p. 285-296, 1989. 
LÓPEZ ULLA, Juan Manuel. El contenido esencial de las libertades de expresión e información según el Tribunal Constitucional español. En SANDLER, Héctor R., El Cuarto Poder. Expresión, Información y Comunicación Social: Ediar, 1999, p. 245-26.

El sentido de la ponderación en las libertades de expresión e información. Estudios de Derecho Público. Homenaje a Juan José RuizRico. Vol. I. Tecnos, p. 620-642.

. Libertad de informar y derecho a expresarse. La jurisprudencia del Tribunal Constitucional: Servicio de Publicaciones de la Universidad de Cádiz, 1994.

MUÑOZ MACHADO, Santiago. Información y derecho al honor: la ruptura del equilibrio. Revista Espańola de Derecho Administrativo, n. 74, p. 165-175, 1992.

PARDO FALCÓN, Javier. Los derechos del artículo 18 de la Constitución española en la jurisprudencia del Tribunal Constitucional. Revista Española de Derecho Constitucional, n. 32, p. 141-178, 1992.

PÉREZ DE LOS COBOS, ORIHUEL, Francisco. Sobre el derecho a la propia imagen (a propósito de la STC 170/1987, de 30 de octubre). Revista del Poder Judicial, n. 10, p. 75-82, 1988.

PÉREZ LUÑO, Antonio E.. Derechos humanos, Estado de Derecho y Constitución: Tecnos, 1990.

REVENGA SÁNCHEZ, Miguel (dir.). Libertad de expresión y discurso del odio. Cuadernos del Cátedra de Democracia y Derechos Humanos, n. 12, 2015.

RODRÍGUEZ MOURULLO, Gonzalo. Liberta de expresión y derecho al honor: criterios jurisprudenciales para la resolución de los conflictos. Estudios sobre la Constitución española. Homenaje al prof. Eduardo García de Enterría. Vol. II. Civitas, 1991, p. 893-906.

ROMERO COLOMA, Aurelia María. Derecho a la intimidad, a la información y proceso penal: Colex, 1987.

SALVADOR CODERCH, Pablo et al. El mercado de las ideas: Centro de Estudios Constitucionales, 1990.

SÁNCHEZ FERRIZ, Remedio. Estudios sobre las libertades públicas: Tirant lo Blanch, 1989. 
SÁNCHEZ GONZÁLEZ, Santiago. La libertad de expresión: Marcial Pons, 1992.

SANTAOLALLA LÓPEZ, Fernando. La jurisprudencia del Tribunal Constitucional sobre la libertad de expresión: una valoración. Revista de Administración Pública, n. 128, p. 185-223, 1992.

SEMPERE RODRÍGUEZ, César; ALZAGA VILLAAMIL, Óscar. Comentario a las leyes políticas. Constitución española: EDERSA, 1984, p. $426-465$.

SOLOZABAL ECHEVARRÍA, Juan José. Libertad de expresión y derecho a la intimidad de los personajes públicos no políticos. Anuario de Derecho Constitucional y Parlamentario de la Comunidad Autónoma de Murcia, n. 2, p. 55-89, 1990.

STUART MILL, John. Sobre la libertad y otros escritos: Ministerio de Trabajo y Seguridad Social, 1991. 